\title{
The analysis of cultivating the autonomous learning ability of foreign students studying in China under the information technology environment
}

\author{
Rui Shen \\ Department of Educational \\ Technology \\ Honghe University \\ Mengzi, China \\ e-mail: shenryx@126.com
}

\author{
Qingqing Yan \\ Department of Educational \\ Technology \\ Honghe University \\ Mengzi, China \\ e-mail: 462702749@qq.com
}

\author{
Wei Huang \\ Office of International Program and \\ Service \\ Honghe University \\ Mengzi, China \\ e-mail: whuangmail@yahoo.com
}

\begin{abstract}
Under the background of growing number of foreign students in China and relative shortage of Chinese teacher for foreigners, improving the autonomous learning ability of foreign students in China is very important. This paper starts out here from the analysis of meaning of foreign students in China's autonomous learning under the environment of information technology, further analyzes the characteristics of foreign students in China's autonomous learning so as to further analyze and discuss how to cultivate foreigner students' autonomous learning ability.
\end{abstract}

Keywords- information technology; foreign students; autonomous learning

\section{INTRODUCTION}

Nowadays, the main learning activities of students are conducted under the school, and the process of teaching in the school environment deeply influences the formation and development of the students' thinking. Foreign students in China are also no exception, and their main learning activities is also formed and developed under the school environment. However, with the rapid popularization and continuous development of information technology, the human's life and learning ways is also changing gradually, and educational mode and way under the information technology take on some new characteristics which inject new vigor and vitality for education field under these new characteristics of information technology. Therefore, simple school teaching mode and way can not provide favorable conditions for cultivating students learning ability. However, the information technology continuously infiltrates education field, which creates a more favorable and positive conditions for strengthening and improving the autonomous learning ability of foreign students..

\section{THE MEANING OF FOREIGN STUDENTS' AUTONOMOUS LEARNING UNDER THE ENVIRONMENT OF INFORMATION TECHNOLOGY}

The autonomous learning is actually that students rely on their own subjective initiative to choose learning time and learning place and control the learning speed within the scope of their own ability according to the demand of selfleaning ability so as to clear what you want to learn. This kind of student-oriented learning ways are collectively called as autonomous learning. Autonomous learning ways usually take the form of individuation, for example, to make a study plan or choose learning tools and resources by oneself so as to truly achieve autonomy on thinking and action of the main body's autonomous learning and make learners improve their learning abilities and change their learning styles.

The judgment standards of autonomous learning mainly is the establishment of learning direction, mastery of learning way and proper self assessment three aspects. These three aspects of standards dominate the improvement of autonomous learning ability, and different learners can reach the different standards. Some learners have strong selfmotivated abilities and self-control abilities, which know how to correctly and effectively choose the learning way and objectively evaluate their own learning achievement; However, there are also many learners with poor selfsupervision ability and self-control ability, and they are hard to form learning objectives and learning methods in the short term even have no ability to form the autonomous learning.

The information technology refers that the collection of techniques which take the computer, media technology and network technology and other kinds of hardware and software as the main tool to support acquisition, storage and transmission of the text, images and sounds and other many kinds of information by the scientific method. In the social context of information technology-oriented, autonomous learning has become the essential basic ability of the students, which is the crucial foundation of foreign students' selfdevelopment. To seek survival and development under the context of information technology, improving the students' autonomous learning ability has been the priority. For current foreign students in China, the computer technology, network technology and media technology under the information technology have become the basic skills the international students must posses. For the foreign students under the information technology, only with the guidance of the teacher, take the independent learning as the core, can school students be ensured to not only acquire the knowledge from the teachers and the precious knowledge and experience in the autonomous learning, but also obtain the learning methods benefiting their lifelong. This method of autonomous learning not only enables the students survive and develop in long term under the context of information technology, but also is a kind of precious wealth on their life roads. 


\section{THE CHARACTERISTICS OF THE STUDENTS AUTONOMOUS LEARNING UNDER INFORMATION TECHNOLOGY}

With the continuous development and popularization of information technology, learning environment of foreign students has changed quite a lot, and these changes are growing amount of information, diversified information dissemination way, more convenient and reliable search way and other aspects. The age of information technology brings a lot of advantages which create some favorable technical conditions for the improvement of students' autonomous learning, make the foreign students freely distribute learning time, selectively choose learning tools and learning places as well as acquire or choose learning resources by themselves.

\section{A. The autonomous learning forms of foreign students' are more flexible and varied}

The traditional teaching mode is static, namely a linear model teaching students with fixed knowledge system, and this model makes the students gradually weaken their autonomous learning abilities. The teaching form under the information technology is dynamic and more varied, which is a kind of nonlinear form linking network with knowledge. Under this form, foreign students can use computer and network and other hard wares or soft wares to complete the process of search, selection and adoption for all kinds of information. Change and variety of education form liberate the foreign students from traditional education mode and make the students more flexibly choose their own cognitive thinking to organize and learn knowledge in order to improve the students' interest in learning knowledge and their abilities of autonomous learning.

\section{B. Foreign students obtain knowledge more self- determinately and more personally}

The information technology environment has created more vivid and varied learning environment and learning objects for foreign students, which can choose proper learning way and learning content according to their own needs of interests and hobbies. At the same time, they also can position learning speed according to their own learning level. Foreign students also can choose to communicate or learn with classmates and teachers by online or even communicate knowledge with experts on the Internet to make the students "autonomy" in the true sense. With the rapid development and popularization of network technology, the network provides the platform of autonomous learning and communication for students, which makes the students' autonomous learning more personalized. On this platform, students can freely analyze the problems existing in the autonomous learning from different angles, enrich their knowledge inventory, improve their own knowledge level, make themselves really know the importance and meaning of the autonomous learning and make their own autonomous learning more efficient and high-quality.

\section{THE STRATEGIES OF CULTIVATING FOREIGN STUDENTS' ABILITY TO STUDY}

The main characteristic of foreign students' autonomous learning is "autonomy", which requires that the student has their own clear learning objectives and learning consciousness during autonomous learning, actively control study time and space, autonomously choose learning methods and learning content so as to complete their learning tasks efficiently. Therefore, under the age of information technology, the ability of foreign students' autonomous learning should be cultivated from the following several aspects.

\section{A. Guide students to form a new learning method, cultivate "self-taught" ability of students}

If foreign students encounter many problems in the learning process, they will choose directly to ask their teachers. At the moment, teachers must guide and inspire students to learn a new learning method but directly answer the problems for them. On this way, students can gradually form a good habit that first tries their best to solve the problems. At the same time, foreign students also will gradually improve their own "self-taught" ability in this process. Under the age of information technology, the teaching method is different from before which most of the time was taken to solve the problems of students. Teaching students all the knowledge in the classroom is impractical, only guide the student to form a new learning method, stimulate students' interest in learning and guarantee students to improve their autonomous learning abilities in search of knowledge and cognitive process. At the same time, foreign students can timely adjust and control the learning speed according to their own conditions and guarantee the good efficiency of learning in the process of "self-taught". Only master new learning method, can foreign students form a habit of "autonomous" learning, independently discover and solve the problems in the learning process and fundamentally improve the autonomous learning ability.

\section{B. The ability of cultivating students to actively obtain all sorts of study resource}

With the development and popularization of information technology, a knowledge and information resource on the net has become more and more. How to obtain the ability of learning resource is the basic requirement of students' autonomous learning. Face to the knowledge ocean under the age of information technology, students should effectively choose useful knowledge resources according to their own learning methods and goals, and learn to create new knowledge through their own thinking mode. Only possess the ability of accessing learning materials, can they effectively conduct autonomous learning and calmly face all kinds of problems in school or after graduation to society.

\section{Change the teaching concept and cultivate the students' learning initiative and enthusiasm}

The change of students' study method directly influences the change of teaching mode. In the teaching mode under the age of information technology, teaching concept is bound to 
change to make teachers guide students to learn well. At the same time, teachers can not simply regard the information technology as a tool for students to search the learning material but really regard the network and computer technology as the hands and feet of students' autonomous learning as well as a real mentor so as to improve the ability of students' autonomous learning. In the process of autonomous learning, students always keep active and positive study state and use the computer and network technology to acquire new learning resources constantly so as to produce new knowledge structure and expand their own thinking. These largely stimulate more foreign students to actively participate in autonomous learning.

Under the age of information technology, students are no longer passive to accept knowledge but take themselves as the core to recreate and transform the knowledge from autonomous learning. In some sense, the change of teaching concept conforms to the requirements of students' autonomous learning under the age of information technology. What's more, it is the key to cultivate and improve the ability of students' autonomous learning.

\section{Sound and thorough teaching management mechanism of autonomous learning}

Under the age of information technology, the teaching mechanism requires to strengthen the communication with students in the process of teaching, understand students' heart and study trend in real-time, timely make a plan or scheme suitable for foreign students' autonomous learning. Make reasonable management mechanism for foreign students' autonomous learning and provide foreign students with good learning environment and atmosphere.

Due to the reasons of students themselves and external environment, foreign students are short of self-awareness and learning awareness to make them be lack of the ability of autonomous learning, which requires that there is the reasonable teaching management mechanism to guide students to adjust learning objectives and learning methods so as to gradually make them possess the self-control ability. This kind of self-control ability will further improve learning level and efficiency of students. Meanwhile students' autonomous learning ability will be gradually formed.

[1] Njiru Joseph N and Waugh Russell F, "Rasch measurement of selfregulated learning in an information and communication technology (ICT)-rich environment”, Journal of applied measurement, 8 (4), Jan. 2007, pp.417-437

[2] Bernacki Matthew L, Byrnes James P and Cromley Jennifer G, “The effects of achievement goals and self-regulated learning behaviors on reading comprehension in technology-enhanced learning environments”, Contemporary Educational Psychology, 37 (2), Apr. 2012, p.148-161

[3] Milei, "Discussion about autonomous learning ability of foreign students and corresponding teaching mechanism of management," Discussion Collection of Education, 2011.

[4] Pang Weiguo, "Autonomous learning--Principles and strategies of learning and teaching,” Shanghai:East China Normal University Press,2003.

[5] Tang Jianlan and Hu Jianbing, “The Environment Design of Internetbased Independent Learning”, Modern Educational Technology,2003 